\title{
Cool runnings: behavioural plasticity and the realised thermal niche of basking sharks
}

\author{
E. M. Johnston · J. D. R. Houghton · P. A. Mayo \\ G. K. F. Hatten • A. P. Klimley • P. J. Mensink
}

Received: 1 February 2021 / Accepted: 30 November 2021 / Published online: 29 January 2022

(C) The Author(s) 2022

\begin{abstract}
Long-distance migrations by marine vertebrates are often triggered by pronounced environmental cues. For the endangered basking shark (Cetorhinus maximus), seasonal changes in water temperature are frequently proposed as a cue for aggregation within (and dispersal from) coastal hotspots. The inference is that such movements reflect year-round occupancy within a given thermal 'envelope'. However, the marked variance in timing, direction and depth of dispersal movements hint at a more nuanced explanation for basking sharks. Here, using data from pop-off archival transmitters deployed on individuals in Irish waters, we explored whether autumnal decreases in water temperature triggered departure from coastal habitats and how depth and location shaped the sharks' realised thermal environment over time. Temperature was not an apparent driver of dispersal from coastal seas, and variance in
\end{abstract}

E. M. Johnston · J. D. R. Houghton ( $\varangle)$ · P. J. Mensink School of Biological Sciences, Queen's University Belfast, 19 Chlorine Gardens, Antrim, Belfast, Co BT9 7DL,

Northern Ireland

e-mail: j.houghton@qub.ac.uk

E. M. Johnston · P. A. Mayo

Irish Basking Shark Group, Inch Island, Co. Donegal, Ireland

E. M. Johnston

National Parks and Wildlife Service, Department of Housing, Local Government and Heritage, North King

Street, Dublin 7 D07 N7CV, Ireland daily temperature ranges reflected occupancy of different habitats; coastal mixed/stratified and offshore subtropical/tropical waters. Furthermore, individuals that moved offshore and into more southern latitudes off Africa, exhibited a distinct daily cycle of deep dives (00:00-12:00, $200 \mathrm{~m}-700 \mathrm{~m} ; 12: 00-00: 00$, 0-300 m), experiencing a more extreme range of temperatures $\left(6.8-27.4{ }^{\circ} \mathrm{C}\right)$, including cooler minimum temperatures, than those remaining in European coastal habitat $\left(9.2-17.6^{\circ} \mathrm{C}\right)$. Collectively, these findings challenge the supposition that temperature serves as a universal driver of seasonal dispersal from coastal seas and prompts further studies of deepwater forays in offshore areas.

Keywords Cetorhinus maximus · Shark migration · Seasonal dispersal - Thermal ecology, Atlantic Ocean $\cdot$ Satellite tracking

P. A. Mayo

Marine and Fisheries Division, Department of Agriculture,

Environment and Rural Affairs, Belfast, BT7 2JA,

Northern Ireland

G. K. F. Hatten · P. J. Mensink

Department of Biology, Biological and Geological

Sciences Building, Western University, London,

ON N6A 5B7, Canada

A. P. Klimley

Department of Wildlife, Fish and Conservation Biology,

University California, Davis, USA 


\section{Introduction}

Animal migrations are defined by their reciprocity and predictability, differentiating them from other movement strategies such as nomadism, invasions and dispersal (e.g. Newson et al. 2009; Teitelbaum and Mueller 2019). For marine vertebrates, the most frequently documented migrations are seasonal (Luschi 2013), with animals moving in response to shifts in prey availability (Corkeron and Connor 1999) and/or physiological constraints aligned with changes in their ambient environment such as water temperature (Schlaff et al. 2014). In response to rapidly warming seas, effective plans for conservation and management must recognise that migration patterns may not be static because migration routes can shift and the timing of migratory movements can be dependent on fluid environmental conditions as they are experienced (Hays et al. 2019; Senner et al. 2020). Such management considerations are magnified for long-distance migrants that traverse territorial boundaries adding a layer of political complexity (e.g. Newson et al. 2009; Mackelworth et al. 2019; Mason et al. 2020).

Seasonal shifts in environmental conditions have been proposed as dispersal cues for basking sharks (Cetorhinus maximus) that aggregate in coastal hotspots at temperate latitudes during summer months, moving typically into offshore areas with the onset of autumn (Sims et al. 2003; Gore et al. 2008; Skomal et al. 2009; Doherty et al. 2017a, 2017b, 2019; Braun et al. 2018; Dolton et al. 2019). Oscillations in plankton abundance provide an intuitive explanation for this pattern (Sims and Reid 2002), but prey densities appear adequate for year-round foraging (Sims 1999) and residence in coastal seas (Doherty et al. 2017a, b). Likewise, water temperature has been proposed frequently as a cue for both seasonal aggregation and subsequent dispersal of basking sharks (NW Atlantic: Skomal et al. 2009; Siders et al. 2013; Braun et al. 2018-NE Atlantic: Berrow and Heardman 1994; Cotton et al. 2005; Priede and Miller 2009; Witt et al. 2012; Miller et al. 2015; Austin et al. 2019; Doherty et al. 2019). The broad inference is that latitudinal movements, triggered by thermal cues, may allow individuals to remain within a given 'envelope' of temperatures (i.e. an optimal thermal range) throughout the year irrespective of season. Certainly, movements of basking sharks in the Northwest Atlantic appear to mirror seasonal changes in water temperature, with individuals ranging from Cape Cod, USA, to tropical waters (Skomal et al. 2009; Hoogenboom et al. 2015; Braun et al. 2018).

Despite evidence of water temperature as a driver of basking shark movements, winter dispersal from coastal seas is not ubiquitous (Gore et al. 2008; Doherty et al. 2017a), raising an interesting question. Quite simply, if migration from coastal areas is to maintain a thermal envelope, why do some animals stay and others disperse? Recent evidence from beyond the Atlantic may provide some insights, with Finucci et al. (2021) revealing that sea surface temperature (SST) aligned poorly with basking shark habitat suitability. Taken together, these findings hint at a more nuanced role for temperature in dispersal, or distinct regional differences in behaviour. Within this overall context, we examined the movements and behaviour of basking sharks in the Northeast Atlantic displaying markedly different 'overwintering' strategies, namely, residency in temperate coastal seas and long-distance dispersal offshore. Using archived temperature, location and depth data relayed via animalborne satellite transmitters, we initially questioned whether decreases in coastal water temperatures during late boreal summer triggered dispersal from coastal seas in the NE Atlantic. Subsequently, we explored how depth and location shaped the sharks' realised thermal environment over time.

\section{Methods}

\section{Device deployment site}

Searches for sharks were conducted during calm (Beaufort Force $<3$ ) sunny conditions to maximise the likelihood of encounters. Basking sharks were tagged between the 26th of July and the 8th of August 2012 at Malin Head, Ireland $\left(55.37^{\circ} \mathrm{N}, 7.40^{\circ} \mathrm{W}\right)$. This deployment time frame was chosen to maximise data recording across autumn and winter months when sharks are known to disperse from coastal seas around Great Britain and Ireland (Sims et al. 2003; Doherty et al. 2017a; Dolton et al. 2019). The waters around Malin Head are a seasonal aggregation area (hotspot) for basking sharks in the North East Atlantic (Johnston et al. 2019). 
Water temperature at the deployment site was recorded year-round, for fisheries purposes by the Irish Marine Institute, using Tidbit temperature probes (location: $7.55028^{\circ} \mathrm{W}, 55.15845^{\circ} \mathrm{N}$ ) deployed at 1-m and 11-m depths (Marine Institute Data Catalogue, 2012). To illustrate the seasonal change in water temperature at the deployment site, we plotted water temperature preceding the tag deployments (April-July/August), the dispersal phase (August) and the post dispersal periods (September-December) (Fig. 1).

Bathymetry data (ocean base layer sources: Esri, GEBCO, NOAA, National Geographic, DeLorme, HERE, Geonames.org and other contributors) were used to determine the location of the west European coastal shelf $(<300-m$-depth contour) with shelf edge and offshore oceanic habitat defined as greater than 300-m depth, after Huthnance et al. (2009).

Device deployment and recovery

During tagging, the size of the shark was estimated with reference to the boat after Bloomfield and Solandt (2008) (i.e. 0-2 m; 3-4 m; 5-6 m; 7-8 m; $8 \mathrm{~m}+$ ). A GoPro Hero with modified dive housing, attached to a 2-m fibreglass painters' pole, was used to gather underwater footage of the genital area from which shark sex could be determined.

Next, Wildlife Computers Mk 10 Pop-off Archival Transmitters with Fastloc GPS (PATF) tags (length: 150 mm; weight in air: $100 \mathrm{~g}$ ) were deployed onto sharks $(n=5)$ by use of a 2 -m fiberglass pole with epoxied applicator from the bow of a $7.4 \mathrm{~m}$ rigid inflatable boat (RIB). Stainless steel aviation wire tethers of 1.2-m length with 5-cm Wildlife Computers titanium (Ti) anchors were used to secure the device in the dorsal musculature to the rear of the shark's dorsal fin. An additional high-density foam float (10-cm length and 5-cm diameter) was fitted mid-way along each tether to maximise surface time and dampen the effect of shark movements on the devices' surface stability.

The PATF tags are hybrid, archival transmitters that record depth, water temperature (accuracy to $\left.0.05{ }^{\circ} \mathrm{C}\right)$, light level $\left(5 \times 10^{-12} \mathrm{~W} \mathrm{~cm}^{-2}\right.$ to $5 \times 10^{-2} \mathrm{~W} \mathrm{~cm}^{-2}$ ), and opportunistically generated Fastloc GPS and ARGOS locations when the transmitter is exposed at the surface. All of the tags were programmed to release from their host shark (popoff), after 140 days of deployment via an electrically corrodible pin. The time interval of 140 days was chosen as a compromise between maximising the period of data collection, likelihood of data recovery and battery longevity (e.g. Musyl et al. 2011). A safety cut-off limit of $15 \%$ of battery power remaining was also set to ensure the tag popped off with sufficient power to transmit archived data via the ARGOS satellite network. Tags were labelled to aid opportunistic recovery by members of the general public should they ultimately be washed ashore.

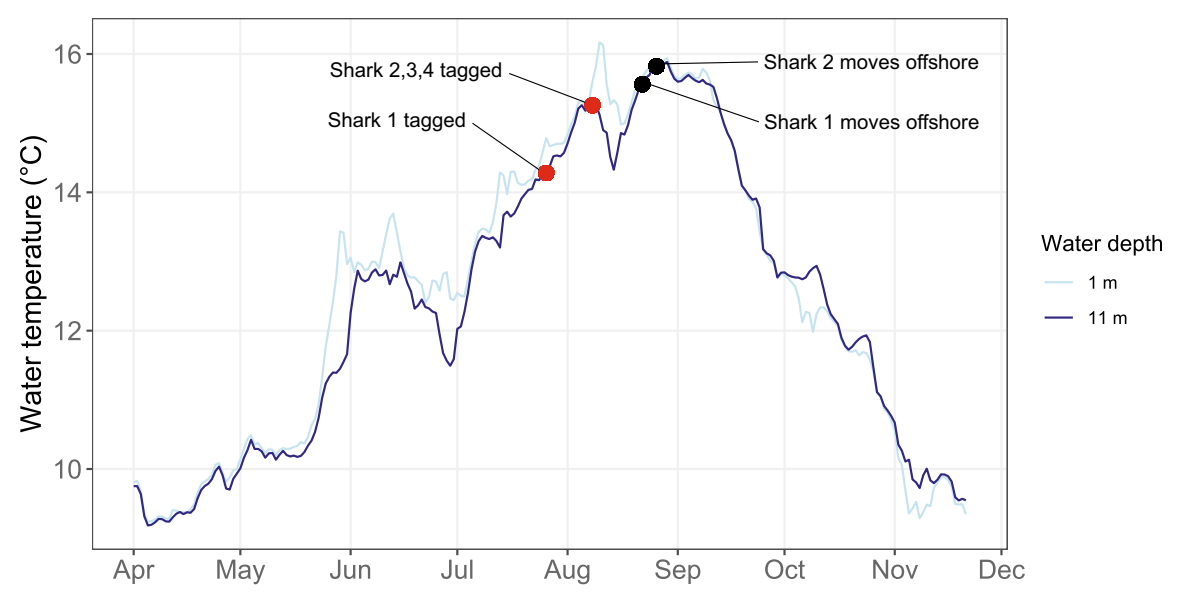

Fig. 1 Water temperature in the study area recorded by Tidbit temperature probe (location: $7.55028^{\circ} \mathrm{W}, 55.15845^{\circ} \mathrm{N}$ ) at $1-\mathrm{m}$ and $11-\mathrm{m}$ depth during the months preceding the PATF tag deployments, dispersal and post dispersal periods. Red points indicate the PATF tag deployment dates for shark 1 (26 July 2012) and 2, 3 and 4 (8 August 2012). Black points show the approximate date of movement offshore $(>300 \mathrm{~m})$ for shark 1 (22 August 2012) and shark 2 (26 August 2012) respectively 
Location data

The PATF tags provided three different location data types including the following: (i) Fastloc GPS locations (for a detailed description of determining positions from Fastloc GPS generated data, see Dujon et al. (2014) and Wensveen et al. (2015)) that were transmitted via the ARGOS satellite network (data received from CLS via ARGOS Direct email service) (ii) ARGOS satellite-derived locations (for a detailed description of deriving positions from multiple ARGOS uplinks, see Costa et al. (2012) and Hoenner et al. (2012)) and (iii) geolocation positions from light level data (for a detailed description of deriving positions from light level data, see Teo et al. (2004) and Braun et al. (2018)).

We used Wildlife Computers Geolocation Processing and modelling software (GPE3) to generate broad latitude derived surface areas of uncertainty (i.e. Lightloc locations) that were subsequently constrained by matching device recorded surface events and water temperature readings (taken at night to avoid solar influence) with corresponding reference data for sea surface temperature and bathymetry to determine the most likely area of location. Historically, estimates of location in offshore areas (where the sharks ranged deeper into the water column) were likely to be associated with broader confidence intervals owing to a reduction in the quality of light data (see Doherty et al. 2017a; Braun et al. 2018). However, the incorporation of 'maximum swimming depth' into the underlying GPE3 Hidden Markov models allows for location refinement by a process of exclusion (i.e. dive depth cannot exceed bathymetry). The resulting surface probability grids were further constrained by a predetermined animal speed parameter to eliminate locations too far to be biologically feasible. The recommended model parameter (Wildlife Computers) is 1.5-2 times the normal cruise speed of the animal. Here, we used a maximum sustained cruise speed for basking sharks of $2 \mathrm{~ms}^{-1}$ after Johnston et al. (2018) and a model parameter of $3.5 \mathrm{~ms}^{-1}$. In addition, when accurate Argos and Fastloc positions were available the GPE3 software used these as 'anchor points' to refine the trajectory of the track and improve the accuracy of the model. Maximum likelihood tracks were then plotted using the ggplot2 package in $\mathrm{R}$ (Wickham 2019).
Depth and temperature data

The PATF tags recorded pressure every second with an accuracy equating to $\sim 10 \mathrm{~cm}$ (i.e. pressure was taken as a proxy for depth in metres) and water temperature every minute to a resolution of $0.05{ }^{\circ} \mathrm{C}$. These raw data were summarised as minimum and maximum depth and minimum and maximum temperature, in four data files daily, covering the predetermined time blocks: 00:00-06:00; 06:00-12:00; 12:00-18:00; 18:00-00:00. For each 6-h time period, the tag recorded the percentage of time the shark spent in five pre-defined temperature bins $\left(<9{ }^{\circ} \mathrm{C}\right.$, $\left.9-12{ }^{\circ} \mathrm{C}, 12-15{ }^{\circ} \mathrm{C}, 15-18{ }^{\circ} \mathrm{C}>18^{\circ} \mathrm{C}\right)$. The four data summary files were then aggregated and combined with available location data (Lightloc) for the 24-h period and subsequently compressed on board the tag (i.e. raw data were not available) for transmission post pop-off. Post pop-off only a representative sample of the compressed data files are transmitted via the ARGOS network.

To compare the depth and temperature ranges experienced by each shark we first calculated moving averages for the maximum and minimum depth and temperature recorded during each 6-h summary period (e.g. 06:00 to 12:00). We used a moving average with an interval of $120 \mathrm{~h}$ to ease data visualisation. Given the summarised nature of the daily data records and the limitations of the representative sample transmitted via satellite, only partial amounts of data are recoverable. When missing data points were encountered the moving average was calculated on the next available data point in the dataset.

We built a Bayesian structural time-series model to compare the temperature profiles of offshore and coastal sharks. Time series intervention analysis can be used to estimate the causal impact of events or interventions on the trajectory of a time series. To accomplish this, the time series of interest is compared to a 'control' time series that has not been exposed to the same intervention. In our case, we were interested in exploring how dispersal off-shore affected the realised thermal environment of sharks compared to those that remained in coastal environments. Using shark 3 as a control time series for remaining in coastal areas, we examined how movement offshore in sharks 1 and 2 impacted the minimum and maximum temperatures experienced. This analysis was completed using the CausalImpact 
function from the CausalImpact $\mathrm{R}$ package (Brodersen et al. 2015).

All data processing and analysis was undertaken in $\mathrm{R}$ statistical computing software ( $\mathrm{R}$ Core Team 2018), and visualised via 'ggplot 2' (Wickham 2019).

\section{Results}

Deployments and data recovery

Five medium-sized sharks (3-6 m) were successfully equipped with PATF tags off Malin Head, Ireland, between 26th of July 2012 and the 8th of August 2012 (Table 1). Three of the tags functioned for the entire deployment period of 140 days, one prematurely popped off after 55 days (shark 4) (Table 1) and one tag did not transmit any data. The reason for the premature pop-off remains unknown, but the shark was at a depth of $37 \mathrm{~m}$ when this occurred, indicating it was not as a result of by-catch (i.e. removed from the shark when taken aboard). One tag (shark 3) was physically recovered post pop-off, resulting in the recovery of additional data beyond that received via transmission (depth and temperature summary files: $n=274$ transmitted; $n=570$ physically recovered and Lightloc fixes; $n=41$ transmitted; $n=219$ physically recovered, noting raw data is not archived). The remaining tags (sharks 1,2 and 4) successfully transmitted a representative range of Lightloc locations and summary depth and temperature data recorded throughout their deployment periods (Table 1). This resulted in the recovery of $100 \%$ of the compressed data files for sharks 3 and 4 during their deployment and $85 \%$ and $75 \%$ of the compressed data files for sharks 1 and 2 respectively. A low number of Argos and Fastloc GPS positions were generated whilst the tags were on the sharks (Table 1) limiting the number of anchor points for the GPE3 model.

Dispersal movements

Within 5 days of transmitter deployment, sharks 1 , 2 and 4 dispersed from the aggregation site in three different directions (Fig. 2), whilst shark 3 remained within close proximity (maximum displacement recorded from deployment site $166 \mathrm{~km}$ ) to the aggregation site throughout the entire deployment period ( $N=140$ days) (Fig. 2). Over the course of the deployments, the four sharks moved into, or remained in, two broadly definable habitat types (i) offshore, including the shelf edge ( $>300-\mathrm{m}$ depth) (sharks 1 and 2) and (ii) coastal $<300-\mathrm{m}$ depth (sharks 3 and 4) (Figs. 2 and 3). More specifically, sharks 1 and 2 displayed wide ranging movements (maximum displacement recorded from deployment site for shark 1: $5004 \mathrm{~km}$; shark 2: $2581 \mathrm{~km}$ ) into offshore tropical $\left(10^{\circ}\right.$ latitude $)$ and subtropical shelf-edge waters $\left(32^{\circ}\right.$ latitude) respectively. Shark 2 did not move back onto the coastal shelf in Northern Spain rather it stayed in waters over $1000 \mathrm{~m}$ deep except for a very brief transit across
Table 1 Details of sharks; transmitter deployment and pop-off dates and locations; number of data files (maxmin temperature, time at temperature, time at depth) and location data received or recovered

\begin{tabular}{|c|c|c|c|c|}
\hline Shark ID & (1) & (2) & (3) & (4) \\
\hline \multicolumn{5}{|l|}{ Deployment } \\
\hline Date & $26 / 07 / 2012$ & 08/08/2012 & 08/08/2012 & 08/08/2012 \\
\hline Lat $\left({ }^{\circ} \mathrm{N}\right)$, long $\left({ }^{\circ} \mathrm{W}\right)$ & $55.337,-7.419$ & $55.231,-7.562$ & $55.378,-7.317$ & $55.371,-7.241$ \\
\hline Sex & $\mathrm{F}$ & not recorded & $\mathrm{F}$ & $\mathrm{F}$ \\
\hline Length & $5-6 \mathrm{~m}$ & $3-4 \mathrm{~m}$ & $5-6 \mathrm{~m}$ & $5-6 \mathrm{~m}$ \\
\hline \multicolumn{5}{|l|}{ Pop-off/recovery } \\
\hline Date & $13 / 12 / 2012$ & $26 / 12 / 2012$ & $26 / 12 / 2012$ & $02 / 10 / 2012$ \\
\hline Lat $\left({ }^{\circ} \mathrm{N}\right)$, long $\left({ }^{\circ} \mathrm{W}\right)$ & $14.739,-31.759$ & $32.215,-10.902$ & $55.268,-6.389$ & $51.299,-5.789$ \\
\hline $\begin{array}{l}\text { Tracking period } \\
\text { (days) }\end{array}$ & 140 & 140 & 140 & 55 \\
\hline Number of data files & 482 & 426 & 570 & 224 \\
\hline $\begin{array}{l}\text { Lightloc locations } \\
(N)\end{array}$ & 208 & 177 & 219 & 123 \\
\hline Fastloc locations $(N)$ & 2 & 4 & 1 & 1 \\
\hline $\begin{array}{l}\text { ARGOS locations } \\
(N)\end{array}$ & 3 & 1 & 0 & 3 \\
\hline
\end{tabular}




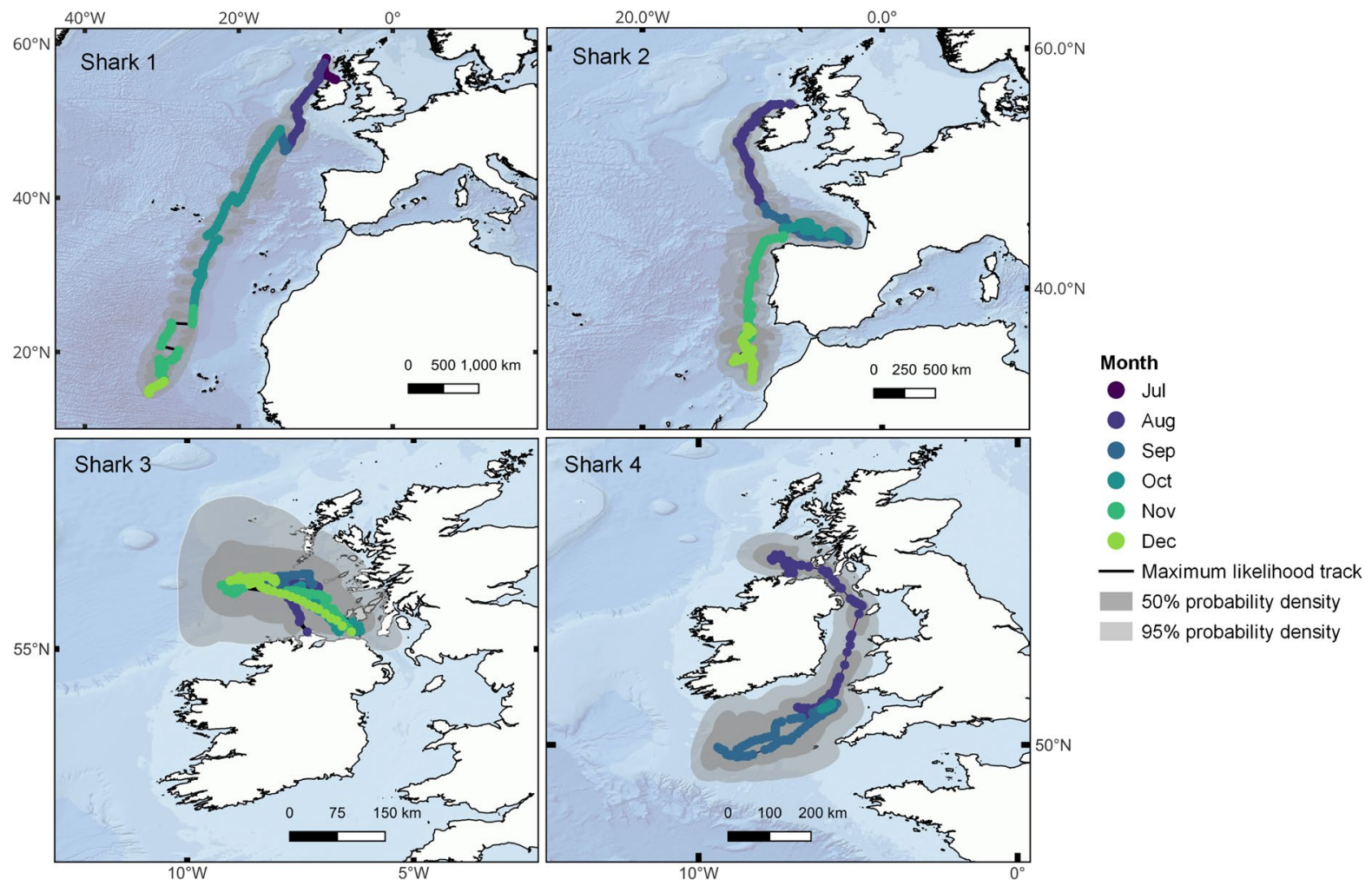

Fig. 2 GPE-3 generated tracks for the four sharks illustrating dispersal routes from the aggregation site at Malin Head and subsequent movement patterns in the Eastern Atlantic. Background colour density indicates depth with darker patches representing greater depths. Ocean base layer sources: Esri, GEBCO, NOAA, National Geographic, DeLorme, HERE, Geonames.org and other contributors (Esri 2019)

\section{Depth and temperature}

Biscay and moves south into deeper waters. In contrast, sharks 3 and 4 remained on the coastal shelf for their entire deployments (shark $3 \mathrm{~N}=140$ days; shark 4: $N=55$ days). Furthermore, shark 4 moved south through the Irish Sea into the Celtic Sea to a known autumnal aggregation area (maximum displacement recorded from deployment site for shark 4: $652 \mathrm{~km}$ ) where the water column is typically stratified (Stéphan et al. 2011) (Fig. 2).

A limited number of Argos and Fastloc GPS anchor points were generated whilst the tags were on the sharks (Table 1) allowing refinement of location estimates en route. Furthermore, as all sharks spent considerable time in the photic zone (either constantly or cyclically) adequate light data were available for the GPE3 processing.
We observed that all sharks continued to range throughout the entire water column (Fig. 3) for the duration of the deployments. However, sharks that moved into offshore waters spent a greater proportion of time below $100 \mathrm{~m}$ (shark 1: 0.66 and shark 2: 0.54) than the sharks that remained on the coastal shelf mum depth recorded for each shark was as follows: shark 1: $1168 \mathrm{~m}$; shark 2: $1168 \mathrm{~m}$; shark 3: $264 \mathrm{~m}$ and shark 4: $280 \mathrm{~m}$.

Sharks 1 and 2 departed offshore (shark 1 on 22 August 2012; shark 2 on 26 August 2012) before water temperatures recorded the seasonal peak $\left(16.0{ }^{\circ} \mathrm{C}\right.$ ) on the 29 of August (Fig. 1). Thereafter, water temperatures were stable at approximately (shark 3: 0.14 and shark 4: 0.02) (Fig. 3). The maxi- 


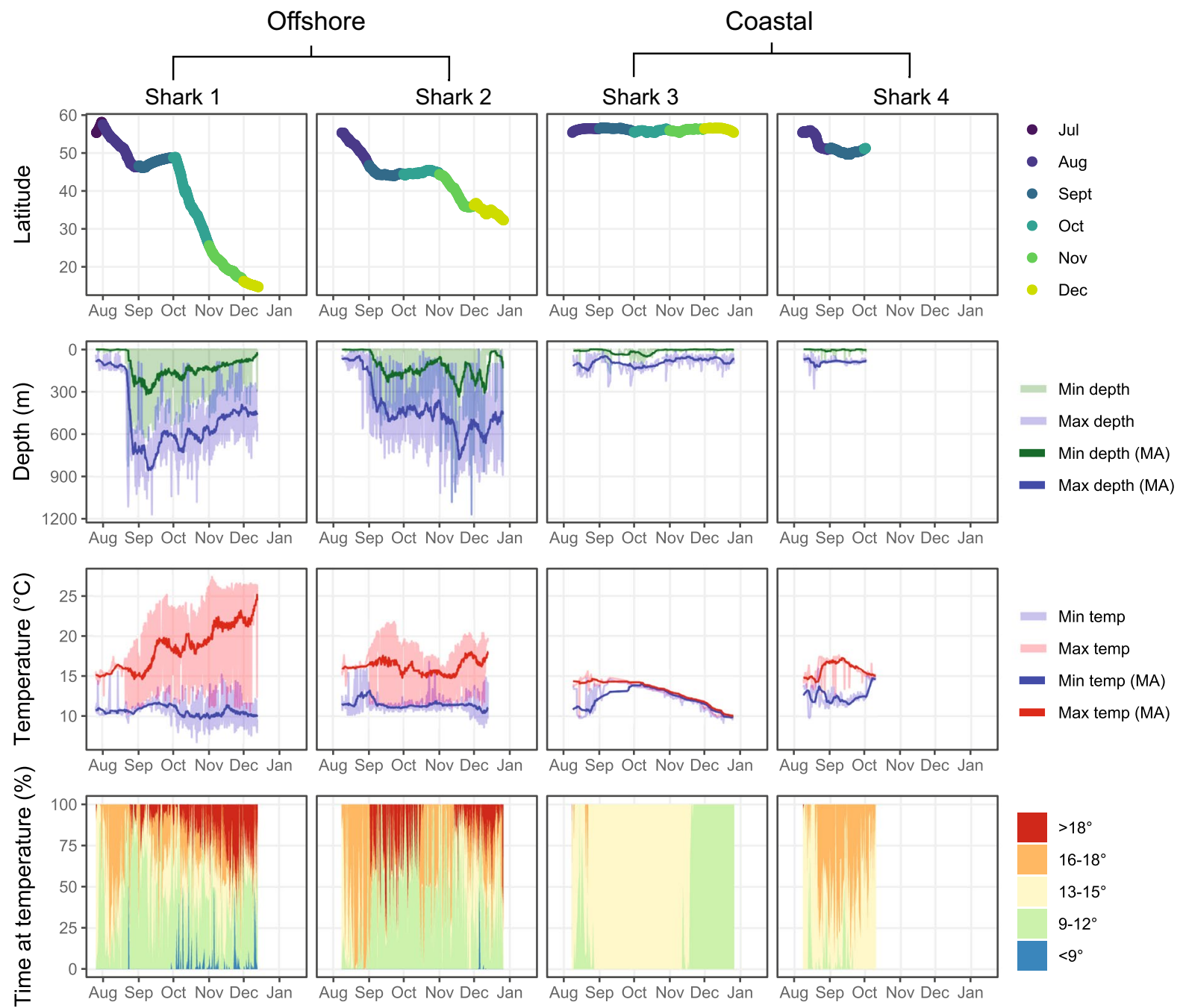

Fig. 3 Latitudinal movements recorded throughout respective deployments, colours represent deployment months; minimum and maximum depths occupied (6-h intervals) over the entire deployment with moving averages (MA) for each time block of 20 observations (i.e. approximately every $120 \mathrm{~h}$ ); minimum and maximum temperatures occupied (6-h intervals) over the entire deployment with moving averages (MA) for each time

half a degree Celsius below the peak value (range $16.0-15.6^{\circ} \mathrm{C}$ ) for a period of 12 days before rapidly deceasing (Fig. 1). Moreover, water temperatures at the deployment site did not drop below the equivalent water temperature recorded on the day of the tag deployments until 24 and 17 days after sharks 1 and 2 had moved offshore, respectively.

Sharks 1 and 2 that moved offshore into more southern latitudes experienced a wider temperature block of 20 observation (i.e. approximately every $120 \mathrm{~h}$ ); time spent in five predefined temperature bins expressed as a percentage of each 6-h interval. For instance, in the month of October shark 3 spends every 6-h interval in 9-12 ${ }^{\circ} \mathrm{C}(100 \%)$ whereas shark 1 regularly spends a portion of each 6-h interval in multiple temperature ranges. Sharks 1 and 2 are considered to be offshore when their maximum depths move below $300 \mathrm{~m}$

range (range $20.6{ }^{\circ} \mathrm{C}: 6.8-27.4{ }^{\circ} \mathrm{C}$ ) than sharks 3 and 4 that remained on the coastal shelf (range $8.4{ }^{\circ} \mathrm{C}$ : 9.2-17.6 ${ }^{\circ} \mathrm{C}$ ) (Fig. 4). Moreover, the sharks that moved offshore into southern latitudes experienced cooler minimum temperatures (shark 1: $6.8^{\circ} \mathrm{C}$; shark 2: $8.6^{\circ} \mathrm{C}$ ) than those concurrently recorded by sharks occupying higher latitudes (shark $3: 9.2{ }^{\circ} \mathrm{C}$; shark 4: $9.8^{\circ} \mathrm{C}$ ) (Fig. 3). Sharks that moved offshore, sharks 1 and 2, experienced significantly higher maximum 
Fig. 4 Variance in the daily depth and temperature ranges for the four individual sharks over their entire deployment periods. Ranges were calculated by subtracting the minimum values from the maximum values over each $24-\mathrm{h}$ period for depth and temperature respectively. Black lines represent median range values for the entire deployment with points representing outliers
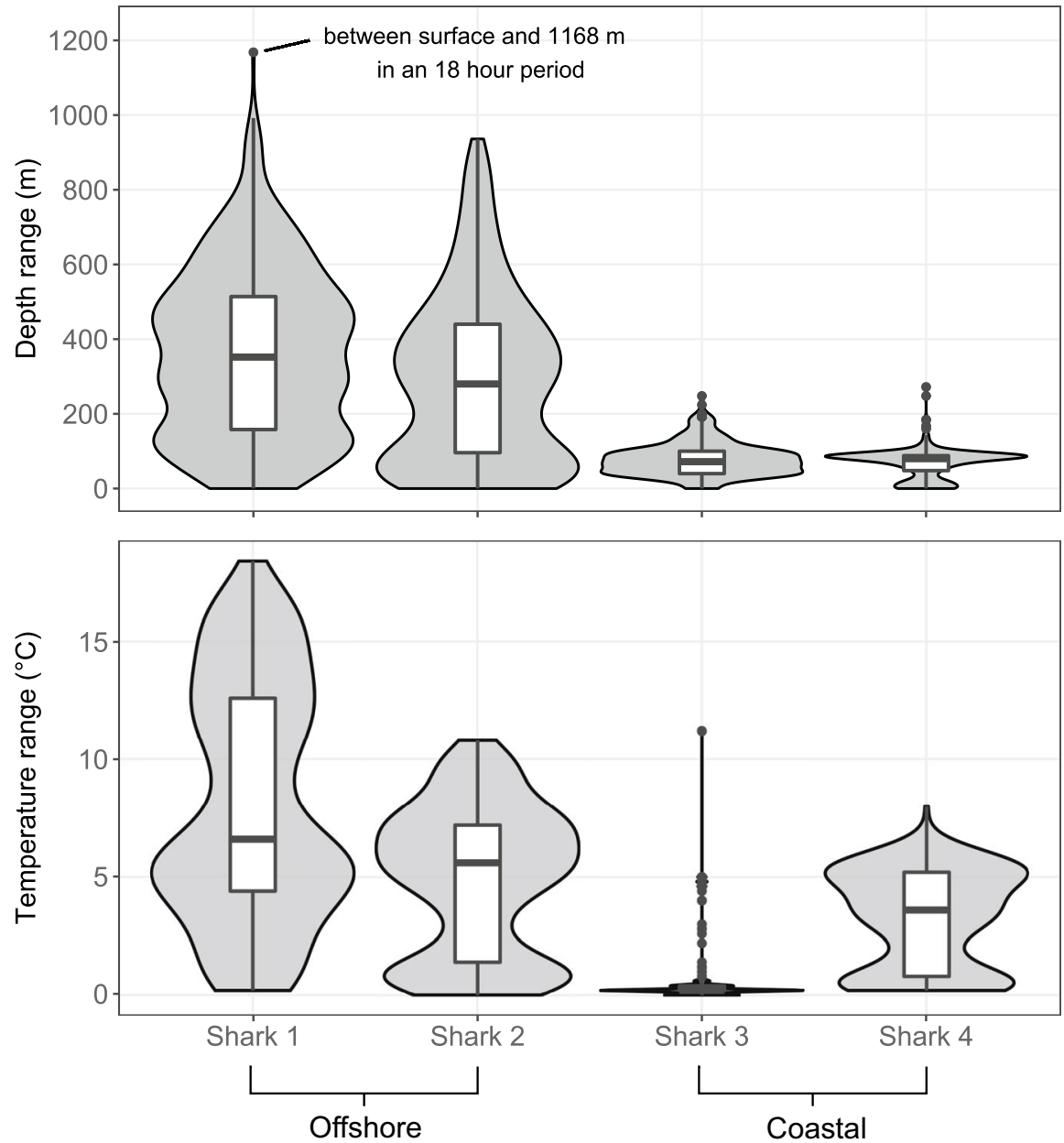

temperatures than shark 3 that remained in coastal waters (Bayesian one-sided tail-area probability $p<0.01)$. Sharks 1 and 2 experienced an increase of $46 \%$ and $15 \%$ in maximum temperatures respectively. Shark 1 had a significant decrease of $10 \%$ in minimum temperatures (Bayesian one-sided tail-area probability $p<0.01$ ), which when combined with maximum temperature increases resulted in a $115 \%$ increase in the temperature range (Bayesian one-sided tail-area probability $p<0.01$ ). Shark 2 minimum temperatures were not significantly different than shark 3 even after moving offshore into warmer surface waters (Bayesian one-sided tail-area probability $p=0.439$ ); however, shark 2 did experience a $33 \%$ increase in temperature range when compared to shark 3 (Bayesian one-sided tail-area probability $p<0.01)$. The contrast in temperature ranges experienced between offshore and onshore sharks reflects the underlying time-attemperature profiles (Fig. 3).

Daily forays through the water column

When sharks 1 and 2 moved off the coastal shelf, they began to undertake deep daily forays into the mesopelagic zone (Fig. 3). Thereafter, sharks 1 and 2 routinely moved into deep waters $(\sim 200-700 \mathrm{~m})$ during the early morning (00:00-06:00 h), returning to shallower waters $(\sim 0-300 \mathrm{~m})$ during the afternoon (12:00-18:00) (Figs. 5 and 6). Conversely, sharks that remained in coastal habitat displayed no apparent diel pattern in-depth use (Fig. 6).

We compared minimum and maximum recorded daily temperatures for sharks 3 and 4 (coastal residents) over the period of 30 of August to 9 of October (i.e. before the tag on shark 4 prematurely detached) 


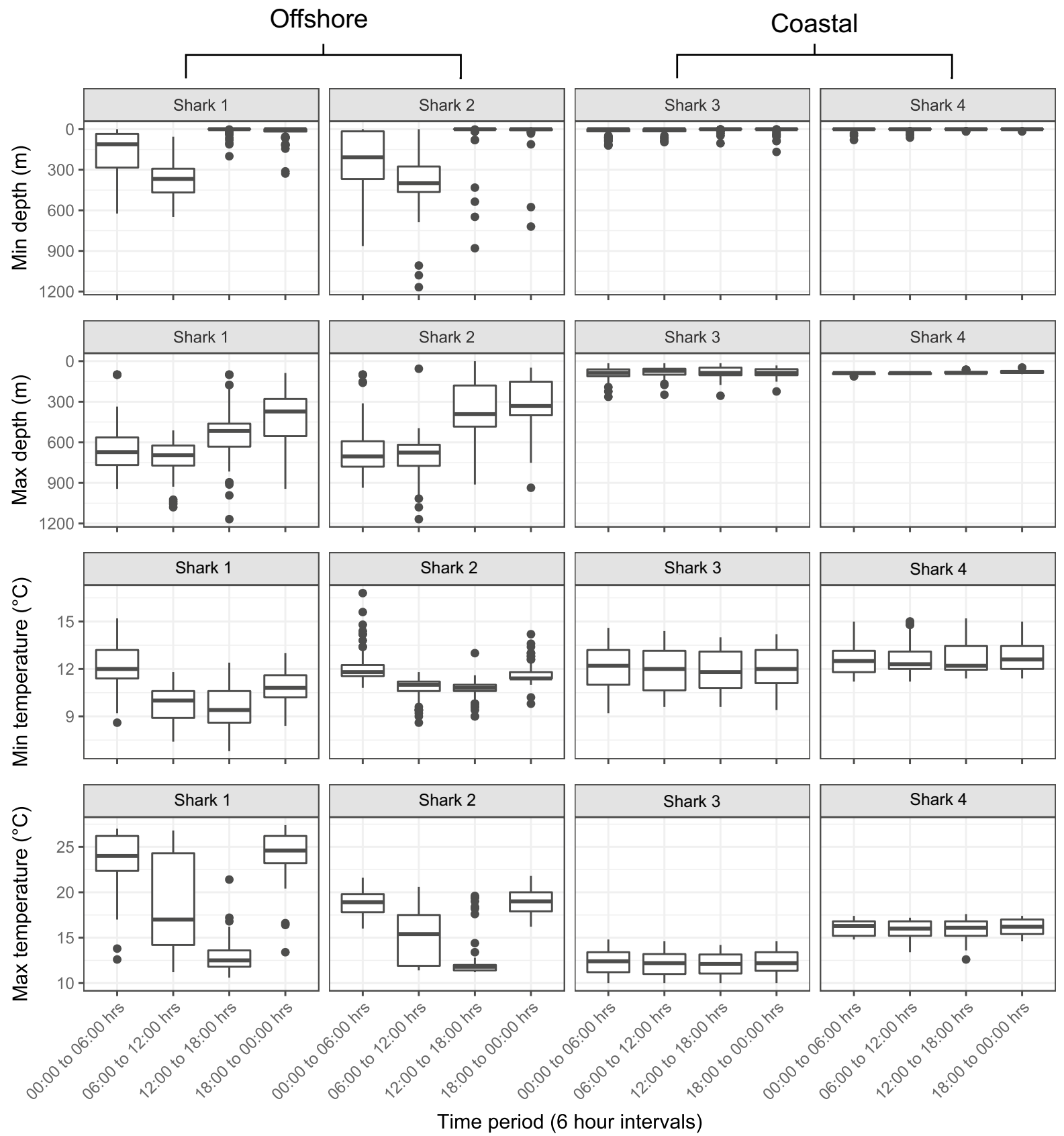

Fig. 5 Boxplots representing minimum depth, maximum depth, minimum temperature and maximum temperature recorded during each of the 6-h intervals over their entire

and found that shark 4 had experienced a wider temperature range than shark 3 (shark 3: $13.6-14.8^{\circ} \mathrm{C}$; shark 4: $11-17.6{ }^{\circ} \mathrm{C}$ ), despite having similar depth deployments. Black lines represent median values with boxes indicating the interquartile range. Outliers are identified with black circles

ranges during this period (Fig. 7). Furthermore, the depth temperature profiles for sharks 3 and 4 that remained in coastal waters indicate that the two 


\section{Shark 1}

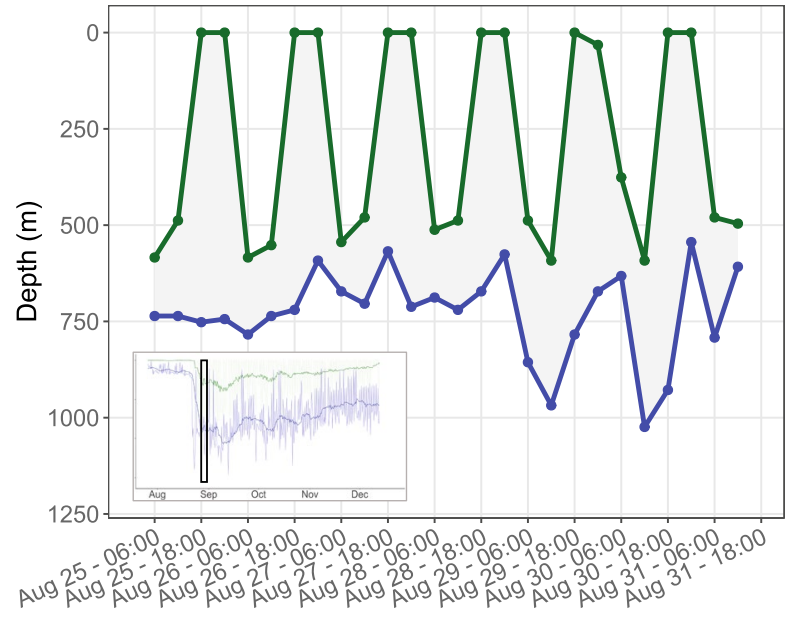

Fig. 6 Sub-sections of dive profiles for offshore sharks 1 and 2 exemplifying deep daily forays into the mesopelagic zone. Minimum (green) and maximum (blue) depths every $6 \mathrm{~h}$ are shown for shark 1 from 25 August-31 August and for shark 2 from 13 to 18 September. Points represent the measurement

sharks concurrently occupied different thermal habitats (Fig. 7) with shark 3 likely in a mixed coastal front whilst, shark 4 was likely in a highly stratified water column.

\section{Discussion}

In an ever-changing climate, identifying how water temperature shapes the distribution of marine life is fundamental for effective conservation on a regional and global scale (Rijnsdorp et al. 2009; Poloczanska et al. 2016; Campana et al. 2020; Payne et al. 2015). However, given the diverse physiologies amongst elasmobranchs (e.g. Watanabe et al., 2015) a 'one-size-fits-all' understanding of thermal range is not appropriate with some species apparently preferring a narrow set of temperatures (e.g. tiger sharks-Payne et al. 2018) whilst others range widely across broad temperature ranges (e.g. white sharks-Boustany et al. 2002). Here, we explored whether the post-aggregation movements of basking sharks reflected the seasonal shift in water temperature in the NE Atlantic (i.e. summer-autumn). Our findings suggested that 'decisions' linked to dispersal or residency might be highly individualised (Shaw 2020), providing further evidence of individual

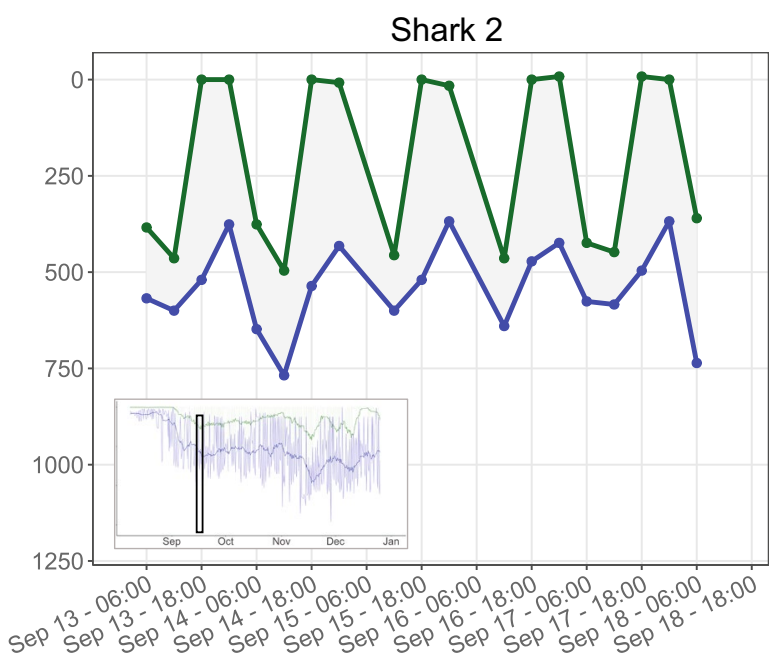

for the preceding $6 \mathrm{~h}$ (i.e. 06:00 points show the minimum and maximum depths recorded from 00:00 to 06:00). Inset plots show full dive profiles for each shark with the section of the dive profile indicated by the black boxes

variation in dispersal dynamics for basking sharks in this region (Doherty et al. 2017a). For example, shark 3 remained exclusively in coastal habitat throughout the winter months, reaffirming that seasonal dispersal from high latitudes is not obligate (Doherty et al. 2017b). Extending this argument, sharks that remained in coastal habitats were not compelled physiologically to move to warmer climes following autumnal decreases in water temperature. Likewise, the offshore movements by sharks 1 and 2 occurred at a time when the water temperature at the deployment site, in NE Atlantic coastal waters, was still increasing (Fig. 1). For basking sharks, identifying whether responses to temperature are regionally adaptive or consistent at a species level will help 'future-proof' management approaches within our changing climate (e.g. Senner et al. 2021; Thorburn et al. 2021; Lennox et al. 2021).

With regards to thermal envelopes, sharks in offshore habitat and more southern latitudes experienced a wider and more extreme range of temperatures $\left(6.8-27.4{ }^{\circ} \mathrm{C}\right)$ than those sharks that remained in coastal habitat at higher latitudes $\left(9.2-17.6{ }^{\circ} \mathrm{C}\right.$; Figs. 3 and 4). Thus, it is improbable that the reason for southerly movements was to remain within a constant temperature range year-round or to move to warmer waters overall. Indeed, sharks 1 and 2 

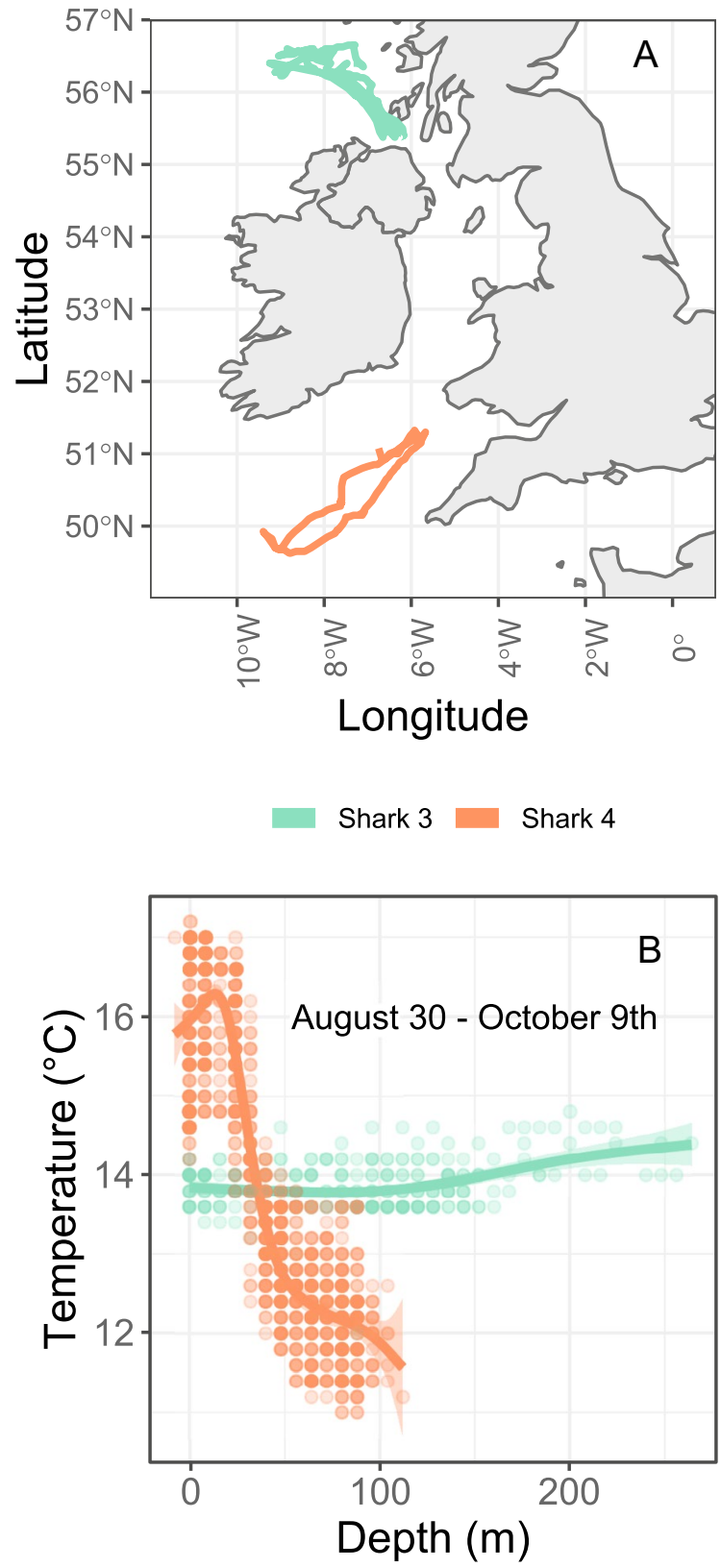

Fig. 7 (A) The location on the coastal shelf of sharks 3 and 4 between August 30 and October 9. (B) The contrasting changes in ambient minimum temperature experienced with depth by sharks 3 and 4 at their respective locations during their overlapping time period (August 30 and October 9). Points are slightly transparent to identify areas of high overlap. Smooth lines for each shark represent a loess fit and shaded areas around the line represent the standard error of the smooth. Minimum temperatures were recorded in-depth bins of $8 \mathrm{~m}$ (e.g. $0-8 \mathrm{~m}, 8-16 \mathrm{~m}, 16-24 \mathrm{~m}$ ) to a precision of $0.2^{\circ} \mathrm{C}$ off the coast of Africa routinely experienced cooler minimum temperatures during the winter than sharks residing off the coasts of Great Britain and Ireland at the same time (Fig. 3). These findings expand the known thermal range for basking sharks in the NE Atlantic from the $8.0-16.0{ }^{\circ} \mathrm{C}$ reported by Doherty et al. (2019) aligning more closely with studies from the NW Atlantic (4.2-29.9 ${ }^{\circ} \mathrm{C}$; Braun et al. 2018). The salient point is that horizontal movements to southerly latitudes alone did not explain the differences in temperature experienced by coastal and offshore sharks (i.e. a 2D conjecture). Rather, it was a combination of location (Fig. 2) and the behavioural shift to deep forays in the offshore that led to the expansion of the realised thermal niche (Figs. 5 and 6). Separately, the sharks that resided continually in coastal habitats (sharks 3 and 4) also experienced markedly different temperature ranges during the autumn and winter (Fig. 4). Differences were driven by the degree of thermal stratification in the water column at their given locations (Fig. 7), which implies that neither residence nor dispersal behaviours served to maintain a constant temperature range over time. These findings again highlight the importance of sub-surface measures of temperature when investigating habitat association in deep-diving species (Edwards et al. 2019).

Any discussions of habitat use must also account for the underlying bathymetry (Cogan et al. 2009) as well as the conditions experienced below the surface (Curtis et al. 2014). For example, deep forays into the water column commenced once individuals moved beyond the shelf edge, with depth emerging as the key determinant of realised thermal niche (Figs. 3 and 6). The distinct periodicity of these forays by sharks 1 and 2 (Fig. 5), indicated that such behaviours were following a daily cycle (Fig. 6), mirroring the vertical distribution of mesopelagic scattering layers (e.g. 400-600 m during day) in the North Atlantic (Klevjer et al. 2016). Deep foraging behaviour has been alluded to previously in the species (Sims et al. 2003; Braun et al. 2018; Doherty et al. 2019) although associations with specific mesopelagic prey remain unknown. This suggestion does not negate other reasons for extensive forays into the water column. For example, oscillatory and or 'yo yo' deep-diving and surfacing events can serve several functions (reviewed by Braun et al. 2022) such as conservation of energy during travel, detection of 
chemical cues, improving magnetic perception and thermoregulation (Nelson et al. 1997; Klimley et al. 2002; Doherty et al. 2019). Unravelling the significance of offshore behaviour (i.e. mesopelagic foraging) is timely given the emergence of regional elasmobranch conservation efforts in the NE Atlantic (Queiroz et al. 2019; Walls and Dulvy 2021). Ireland, as a member of the European Union, has a significant role to play in the management of migratory marine species such as the endangered basking shark (Sims et al. 2015) that reside within or frequent its expansive territorial waters (i.e. EEZ $880,000 \mathrm{~km}^{2}$ ). Here, we reiterate that offshore areas (traversing Ireland's EEZ and beyond) likely constitute more than simple migratory pathways for the species (Doherty et al. 2017a), further highlighting the requirement for dedicated study beyond well-established coastal hotspots (Sims 2008).

From a physiological perspective, the oscillating excursions from the surface to depth (Fig. 6) may serve a similar function to those reported for other large-bodied pelagic sharks (Queiroz et al. 2017) such as tiger sharks Galeocerdo cuvier (Nakamura et al. 2011), whale shark Rhincodon typus (Meekan et al. 2015) and the bluntnose sixgill shark Hexanchus griseus (Coffey et al. 2020) that are required to move to surface waters regularly to rewarm. Arguably, basking sharks' large mass (Mathews and Parker 1950) and substantial stores of liver oil (Tsujimoto 1935) might dampen the rate of heat diffusion allowing them to temporarily access cold water prey at depth in open ocean areas, where surface prey fields are more depleted. Indeed, the concept of 'thermal inertia' in other large deep-diving sharks is well established (e.g. Carey et al. 1981; Kitagawa and Kimura 2006; Thums et al. 2013; Meekan et al. 2015; Howey et al. 2016) and warrants further attention in the species.

In summary, our data from the NE Atlantic revealed no apparent link between the timing of offshore dispersal in basking sharks and water temperature, nor a sustained thermal envelope over time. Irrespective of latitude, depth use was the key determinant of thermal range (and minimum temperatures) within coastal and offshore areas. We avoid extrapolating these findings across the Atlantic and simply suggest that thermal responses might be regionally adaptive. Finally, from a management perspective, basking sharks in the NE Atlantic may possess the adaptive capacity to tolerate projected shifts in water temperature linked to climate change. However, this conjecture is premature without a clearer understanding of why basking sharks range so extensively and continuously throughout the world's oceans.

Acknowledgements We thank the following for their input and assistance: the fieldwork research team of the Inishowen Basking Shark Study Group; Heather Vance, Donal Griffin, Boyd Bryce, Rosemary McCloskey and Danny McFadden; Wildlife Computers staff particularly Suzy Kohin; Matthew Witt; the University of Exeter for assistance with location projections and review of this study as a thesis chapter; and Alex McInturf for input to the general discussion. We acknowledge the Marine Institute, Ireland, for use of water temperature data.

Author contribution EJ and JH undertook the study conception and design. EJ and PAM undertook material preparation and data collection. Analysis was performed by PJM, EJ and GH. The first draft of the manuscript was written by EJ, $\mathrm{JH}$ and PJM and all authors commented on previous versions of the manuscript. All authors read and approved the final manuscript.

Funding This work was supported by the Inishowen Development Partnership via the European Union LEADER Fund through the Irish Basking Shark Study Group, Monster Munch Project.

Inishowen Development Partnership LEADER EU FUND

Data availability All data are stored on the secure 'Pure' server at Queen's University Belfast maintained by central IT support. Data will be accessible in line with science publication protocols from the authors on request.

Code availability Data will be accessible in line with science publication protocols from the authors on request.

\section{Declarations}

Ethics approval Experimental procedures complied with the Department of Agriculture, Food and Marine, Ireland Animal Welfare Guidelines, and were approved by the National Parks and Wildlife Service, Department of Arts, Culture and Gaeltacht, Ireland. The research did not pose a threat to population viability.

Consent to participate All authors have provided consent; no other consents are required.

Consent for publication All authors have provided consent; no other consents are required.

Conflict of interest The authors declare no competing interests.

Open Access This article is licensed under a Creative Commons Attribution 4.0 International License, which permits 
use, sharing, adaptation, distribution and reproduction in any medium or format, as long as you give appropriate credit to the original author(s) and the source, provide a link to the Creative Commons licence, and indicate if changes were made. The images or other third party material in this article are included in the article's Creative Commons licence, unless indicated otherwise in a credit line to the material. If material is not included in the article's Creative Commons licence and your intended use is not permitted by statutory regulation or exceeds the permitted use, you will need to obtain permission directly from the copyright holder. To view a copy of this licence, visit http://creativecommons.org/licenses/by/4.0/.

\section{References}

RA Austin LA Hawkes PD Doherty S Henderson R Inger L Johnson SK Pikesley J-L Solandt C Speedie MJ Witt 2019 Predicting habitat suitability for basking sharks (Cetorhinus maximus) in UK waters using ensemble ecological niche modelling J Sea Res 153101767 https://doi.org/10. 1016/j.seares.2019.101767

Berrow SD and Heardman C (1994) The basking shark Cetorhinus maximus (Gunnerus) in Irish waters - patterns of distribution and abundance. Biol Environ. Proceedings of the Royal Irish Academy 94B (2), 101-107. http:// www.jstor.org/stable/20499923.

Bloomfield A \& Solandt J L (2008) Marine Conservation Society Basking Shark Watch: 20 year report (1987-2006). Marine Conservation Society, Ross on Wye, UK.

CD Braun MC Arostegui SR Thorrold YP Papastamatiou P Gaube J Fontes P Afonso 2022 The functional and ecological significance of deep diving by large marine predators Ann Rev Mar Sci 141 https://doi.org/10.1146/annur ev-marine-032521-103517

C Braun G Skomal S Thorrold 2018 Integrating archival tag data and a high-resolution oceanographic model to estimate basking shark (Cetorhinus maximus) movements in the Western Atlantic Front Mar Sci 5103389 https://doi. org/10.3389/fmars.2018.00025

KH Brodersen F Gallusser J Koehler N Remy SL Scott 2015 Inferring causal impact using Bayesian structural timeseries models Ann Appl Stat 91247274 https://doi.org/ 10.1214/14-AOAS788

S Campana R Stefánsdóttir K Jakobsdottir J Sólmundsson 2020 Shifting fish distributions in warming sub-Arctic oceans Sci Rep 1016448 https://doi.org/10.1038/ s41598-020-73444-y

FG Carey JM Teal JW Kanwisher 1981 The visceral temperatures of mackerel sharks (Lamnidae) Physiol Zoo 543334 344 https://doi.org/10.1086/physzool.54.3.30159948

DM Coffey MA Royer CG Meyer KN Holland 2020 Diel patterns in swimming behavior of a vertically migrating deepwater shark, the bluntnose sixgill (Hexanchus griseus) PLoS ONE 151 e0228253 https://doi.org/10.1371/ journal.pone.0228253

CB Cogan BJ Todd P Lawton TT Noji 2009 The role of marine habitat mapping in ecosystem-based management ICES J
Mar Sci 66920332042 https://doi.org/10.1093/icesjms/ fsp214

PJ Corkeron RC Connor 1999 Why do baleen whales migrate? Mar Mamm Sci 15412281245 https://doi.org/10.1111/j. 1748-7692.1999.tb00887.x

DP Costa GA Breed PW Robinson 2012 New Insights into pelagic migrations: implications for ecology and conservation Ann Rev Ecol Evol Syst 437396 https://doi.org/ 10.1146/annurev-ecolsys-102710-145045

PA Cotton DW Sims S Fanshawe M Chadwick 2005 The effects of climate variability on zooplankton and basking shark (Cetorhinus maximus) relative abundance off the southwest Britain Fish Oceanogr 142151155 https://doi. org/10.1111/j.1365-2419.2005.00331.x

Curtis T H, Zeeman SI, Summers EL, Cadrin SX and Skomal GB (2014) Eyes in the sky: linking satellite oceanography and biotelemetry to explore habitat selection by basking sharks. Anim Biotelemetry, 2(12). https://doi.org/10.1186/ 2050-3385-2-12

PD Doherty JM Baxter FR Gell BJ Godley RT Graham G Hall J Hall LA Hawkes SM Henderson L Johnson C Speedie MJ Witt 2017a Long-term satellite tracking reveals variable seasonal migration strategies of basking sharks in the north-east Atlantic Sci Rep 742837 https://doi.org/10. 1038/srep42837

P Doherty J Baxter B Godley R Graham G Hall J Hall L Hawkes S Henderson L Johnson C Speedie M Witt 2017b Testing the boundaries: seasonal residency and inter-annual site fidelity of basking sharks in a proposed Marine Protected Area Biol Cons 2096875 https://doi. org/10.1016/j.biocon.2017.01.018

PD Doherty JM Baxter BJ Godley RT Graham G Hall J Hall LA Hawkes S Henderson L Johnson C Speedie MJ Witt 2019 Seasonal changes in basking shark vertical space use in the north-east Atlantic Mar Biol 166129 https:// doi.org/10.1007/s00227-019-3565-6

Dolton H, Gell F, Hall J, Hall G, Hawkes L and Witt MJ (2019) Assessing the importance of Isle of Man waters for the basking shark Cetorhinus maximus. Endanger Species Res. 41. https://doi.org/10.3354/esr01018. http://dx.doi.org/https://doi.org/10.3354/esr01018

Dujon A, Lindstrom T and Hays G (2014) The accuracy of Fastloc-GPS locations and implications for animal tracking. Methods Ecol Evol, 5(11). https://doi.org/10. 1111/2041-210X.12286

J Edwards J Pratt N Tress N Hussey 2019 Thinking deeper: uncovering the mysteries of animal movement in the deep sea Deep Sea Res Part I 1462443 https://doi.org/ 10.1016/j.dsr.2019.02.006

Esri. "Ocean Basemap" [basemap]. 1:577k (2019). https:// www.arcgis.com/home/item.html?id=6348e67824504fc 9a62976434bf0d8d5. Accessed 31 August 2021.

Finucci, B., Duffy, C. A., Brough, T., Francis, M. P., Milardi, M., Pinkerton, M. H., ... \& Stephenson, F. (2021) Drivers of spatial distributions of basking shark (Cetorhinus maximus) in the southwest Pacific. Frontiers in Marine Science, 8, 419

Gore M A, Rowat D, Hall J, Gell FR and Ormond RF (2008) Transatlantic migration and deep mid-ocean diving by basking shark. Biol Lett 4(4). https://doi.org/10.1098/ rsbl.2008.0147 
Hays G, Bailey H, Bograd S, Bowen W, Campagna C, Carmichael R, Casale P, Chiaradia A, Costa D, Cuevas E, De Bruyn N, Dias M, Duarte C, Dunn D, Dutton HP, Esteban N, Friedlaender A, Goetz K, Godley B and Sequeira A (2019) Translating marine animal tracking data into conservation policy and management. Trends Eco Evol 34, https://doi.org/10.1016/j.tree.2019.01.009

Hoenner X, Whiting S, Hindell M and McMahon C (2012) Enhancing the use of Argos satellite data for home range and long-distance migration studies of marine animals. PloS One. 7. https://doi.org/10.1371/journal.pone. 0040713

J Hoogenboom S Wong R Ronconi H Koopman L Murison A Westgate 2015 Environmental predictors and temporal patterns of basking shark (Cetorhinus maximus) occurrence in the lower Bay of Fundy Canada J Exp Mar Biol Ecol 4652432 https://doi.org/10.1016/2Fj.jembe.2015. 01.005

LA Howey ER Tolentino YP Papastamatiou EJ Brooks DL Abercrombie YY Watanabe S Williams A Brooks DD Chapman LK Jordan 2016 Into the deep: the functionality of mesopelagic excursions by an oceanic apex predator Eco Evol $61552905304 \mathrm{https} / / /$ doi.org/10.1002/ ece 3.2260

JM Huthnance JT Holt SL Wakelin 2009 Deep ocean exchange with west-European shelf seas Ocean Sci 5 621634 https://doi.org/10.5194/os-5-621-2009

Johnston EM, Halsey GL, Payne NL, Kock AA, Iosilevskii G, Whelan B and Houghton JDR (2018) Latent power of basking sharks revealed by exceptional breaching events. Biol Lett, 14(9). https://doi.org/10.1098/rsbl.2018.0537

EM Johnston PA Mayo PJ Mensink E Savetsky JDR Houghton 2019 Serendipitous re-sighting of a basking shark Cetorhinus maximus reveals inter-annual connectivity between American and European coastal hotspots J Fish Biol 956 15301534 https://doi.org/10.1111/jfb.14163

T Kitagawa S Kimura 2006 An alternative heat-budget model relevant to heat transfer in fishes and its practical use for detecting their physiological thermoregulation Zoolog Sci 231210651071 https://doi.org/10.2108/zsj.23.1065

T Klevjer X Irigoien A Røstad E Fraile-Nuez VM Benítez-Barrios S Kaartvedt 2016 Large scale patterns in vertical distribution and behaviour of mesopelagic scattering layers Sci Rep 619873 https://doi.org/10.1038/srep19873

AP Klimley SC Beavers TH Curtis SJ Jorgensen 2002 Movements and swimming behavior of three species of sharks in La Jolla Canyon, California Environ Biol Fishes 63117 135 https://doi.org/10.1023/A:1014200301213

RJ Lennox CP Paukert K Aarestrup 2019 One hundred pressing questions on the future of global fish migration science, conservation, and policy Front Ecol Evol 7286 https://doi.org/10.3389/fevo.2019.00286

P Luschi 2013 Long-distance animal migrations in the oceanic environment: orientation and navigation correlates ISRN, Zool 20133631839 https://doi.org/10.1155/2013/631839

HL Mathews HW Parker 1950 Notes on the anatomy and biology of the basking shark (Cetorhinus maximus (Gunner)) Proc Zool Soc Lond 120535576 https://doi.org/10. 1111/j.1096-3642.1950.tb00663.x
N Mason M Ward JEM Watson 2020 Global opportunities and challenges for transboundary conservation Nat Ecol Evol 4694701 https://doi.org/10.1038/s41559-020-1160-3

P Mackelworth Y Seker F Vega 2019 Geopolitics and marine conservation: synergies and conflicts Front Mar Sci 6759 https://doi.org/10.3389/fmars.2019.00759

M Meekan AL Fuiman R Davis Y Berger M Thums 2015 Swimming strategy and body plan of the world's largest fish: implications for foraging efficiency and thermoregulation Front Mar Sci 264 https://doi.org/10.3389/fmars. 2015.00064

PI Miller KL Scales SN Ingram EJ Southall DW Sims 2015 Basking sharks and oceanographic fronts: quantifying associations in the north-east Atlantic Funct Ecol 298 10991109 https://doi.org/10.1111/1365-2435.12423

M Musyl M Domeier N Nasby-Lucas R Brill M McNaughton Y Swimmer M Lutcavage S Wilson B Galuardi J Liddle 2011 Performance of pop-up satellite archival tags Mar Ecol Prog Ser 433128 https://doi.org/10.3354/meps0 9202

I Nakamura YY Watanabe YP Papastamatiou K Sato CG Meyer 2011 Yo-yo vertical movements suggest a foraging strategy for tiger sharks Galeocerdo cuvier Mar Ecol Prog Ser 424237246 https://doi.org/10.3354/meps08980

DR Nelson JN Mckibben WR Strong CG Lowe JA Sisneros DM Schroeder RJ Lavenberg 1997 An acoustic tracking of a megamouth shark, Megachasma pelagios: a crepuscular vertical migrator Environ Biol Fishes 49389399 https://doi.org/10.1023/A:1007369619576

S Newson S Mendes H Crick N Dulvy JDR Houghton GC Hays AM Hutson CD MacLeod GJ Pierce RA Robinson 2009 Indicators of the impact of climate change on migratory species Endanger Species Res 72101113 https://doi. org/10.3354/esr00162

NL Payne JA Smith DE Meulen Van Der MD Taylor YY Watanabe A Takahashi TA Marzullo CA Gray G Cadiou IM Suthers B Sinclair 2016 Temperature dependence of fish performance in the wild: links with species biogeography and physiological thermal tolerance Funct Ecol 30903 912 https://doi.org/10.1111/1365-2435.12618

Payne, N. L., Meyer, C. G., Smith, J. A., Houghton, J. D., Barnett, A., Holmes, B. J., ... \& Halsey, L. G. (2018) Combining abundance and performance data reveals how temperature regulates coastal occurrences and activity of a roaming apex predator. Global change biology, 24(5), 1884-1893

Poloczanska ES, Burrows MT, Brown CJ, García Molinos J, Halpern BS, Hoegh-Guldberg O, Kappel CV, Moore PJ, Richardson AJ, Schoeman DS \& Sydeman WJ (2016) Responses of marine organisms to climate change across oceans. Front Mar Sci, 3:62. https://doi.org/10.3389/ fmars.2016.00062

IG Priede P Miller 2009 A basking shark (Cetorhinus maximus) tracked by satellite together with simultaneous remote sensing II: new analysis reveals orientation to a thermal front Fish Res 95 2-3 370372 https://doi.org/10. 1016/j.fishres.2008.09.038

N Queiroz C Vila-Pouca A Couto EJ Southall G Mucientes NE Humphries DW Sims 2017 Convergent foraging tactics of marine predators with different feeding strategies across 
heterogeneous ocean environments Front Mar Sci 4115 https://doi.org/10.3389/fmars.2017.00239

N Queiroz N Humphries A Couto M Vedor 2019 Global spatial risk assessment of sharks under the footprint of fisheries Nature 572461466 https://doi.org/10.1038/ s41586-019-1444-4

R Core Team (2018) R: a language and environment for statistical computing. R Foundation for Statistical Computing, Vienna, Austria. URL https://www.R-project.org/.

AD Rijnsdorp MA Peck GH Engelhard C Mollmann JK Pinnegar 2009 Resolving the effect of climate change on fish populations ICES J Mar Sci 66715701583 https://doi. org/10.1093/icesjms/fsp056

AM Schlaff MR Heupel CA Simpfendorfer 2014 Influence of environmental factors on shark and ray movement, behaviour and habitat use: a review Rev Fish Biol Fish 244 10891103 https://doi.org/10.1007/s11160-014-9364-8

N Senner Y Morbey B Sandercock 2020 Editorial: Flexibility in the migration strategies of animals Front Ecol Evol 8 $111 \mathrm{https}: / /$ doi.org/10.3389/fevo.2020.00111

Shaw AK (2020) Causes and consequences of individual variation in animal movement. Move Ecol, 8(12). https://doi. org/10.1186/s40462-020-0197-x

GB Skomal SI Zeeman JH Chisholm EL Summers HJ Walsh KW McMahon SR Thorrold 2009 Trans-equatorial migrations by basking sharks in the western Atlantic Ocean Curr Biol 191210191022 https://doi.org/10.1016/j.cub. 2009.04.019

ZA Siders AJ Westgate DW Johnston LD Murison HN Koopman 2013 Seasonal variation in the spatial distribution of basking sharks (Cetorhinus maximus) in the Lower Bay of Fundy Canada Plos One 812 e82074 https://doi.org/10. 1371/journal.pone.0082074

Sims D, Fowler SL, Clò S, Jung A, Soldo A and Bariche M (2015) Cetorhinus maximus, The IUCN Red List of Threatened Species 2015. Accessed 10 July 2019.

DW Sims 2008 Sieving a living: a review of the biology, ecology and conservation status of the plankton-feeding basking shark Cetorhinus maximus Adv Mar Biol 54171220 https://doi.org/10.1016/s0065-2881(08)00003-5

DW Sims 1999 Threshold foraging behaviour of basking sharks on zooplankton: life on an energetic knife edge? Proc Royal Soc B 26614271437 https://doi.org/10.1098/ 2Frspb.1999.0798

DW Sims PC Reid 2002 Congruent trends in long-term zooplankton decline in the north-east Atlantic and basking shark (Cetorhinus maximus) fishery catches off west Ireland Fish Oceanogr 1115963 https://doi.org/10.1046/j. 1365-2419.2002.00189.x

D Sims E Southall A Richardson P Reid J Metcalfe 2003 Seasonal movements and behaviour of basking sharks from archival tagging: no evidence of winter hibernation Mar
Ecol Prog Ser 248187196 https://doi.org/10.3354/meps2 48187

Stéphan E, Gadenne H and Jung A (2011) Sur les traces du requin pélerin, Satellite tracking of basking sharks in the North-east Atlantic Ocean, final rreport. Association pour L'Etude et la Conservation des Sélaciens. Brest, France.

C Teitelbaum T Mueller 2019 Beyond migration: causes and consequences of nomadic animal movements Trends Ecol Evol 346569581 https://doi.org/10.1016/j.tree.2019.02. 005

SLH Teo A Boustany S Blackwell A Walli KC Weng B Block 2004 Validation of geolocation estimates based on light level and sea surface temperature from electronic tags Mar Ecol Prog Ser 2838198 https://doi.org/10.3354/meps2 83081

J Thorburn F Neat I Burrett L-A Henry DM Bailey CS Jones LR Noble 2019 Ontogenetic variation in movements and depth use, and evidence of partial migration in a benthopelagic elasmobranch Front Ecol Evol 7353 https://doi.org/10.3389/fevo.2019.00353

Thums M, Meekan M, Stevens J, Wilson S and Polovina J (2013) Evidence for behavioural thermoregulation by the world's largest fish. J Royal Soc Interface, 10(78). https:// doi.org/10.1098/rsif.2012.0477

Tsujimoto M (1935) On basking shark liver oil. Bull Chem Soc Jpn, 10(4). https://doi.org/10.1246/bcsj.10.144

UNEP/ CMS (1979) UN convention on the conservation of migratory species of wild animals. CMS or Bonn Convention. UNEP/CMS Secretariat.

RHL Walls NK Dulvy 2021 Tracking the rising extinction risk of sharks and rays in the Northeast Atlantic Ocean and Mediterranean Sea Sci Rep 11115397 https://doi.org/10. 1038/s41598-021-94632-4

Wensveen P, Thomas L and Miller PJO (2015) A path reconstruction method integrating dead-reckoning and position fixes applied to humpback whales. Mov Ecol, 3(31). https://doi.org/10.1186/s40462-015-0061-6

H Wickham 2019 ggplot2: Elegant Graphics for Data Analysis Springer-Verlag New York

M Witt T Hardy L Johnson C McClellan S Pikesley S Ranger P Richardson JL Solandt C Speedie R Williams 2012 Basking sharks in the northeast Atlantic: spatio-temporal trends from sightings in UK waters Mar Ecol Prog Ser 459121134 https://doi.org/10.3354/meps09737

Publisher's note Springer Nature remains neutral with regard to jurisdictional claims in published maps and institutional affiliations. 